\title{
Prins Cyclization Catalyzed by a Fe(III)/TMS System: A [2+2] Cycloaddition versus Oxocarbenium ion Pathway Study
}

\author{
Sixto J. Pérez, ${ }^{[a]}$ Martín Purino, ${ }^{[a]}$ Pedro O. Miranda, ${ }^{[c]}$ Víctor S. Martín, ${ }^{*[a]}$ Israel Fernández, ${ }^{*[b]}$ and Juan I. Padrón ${ }^{\star[a],[c]}$
}

\begin{abstract}
The different factors that control the alkene Prins cyclization catalyzed by iron(III) salts have been explored by means of a joint experimental-computational study. The system iron(III) salt/TMSX has proved to be an excellent promoter in the synthesis of crossed all-cis disubstituted tetrahydropyrans, minimizing the formation of products derived from side-chain exchange. In this iron(III)-catalyzed Prins cyclization reaction between homoallylic alcohols with non-activated alkenes two mechanistic pathways can be envisaged, namely the classical oxocarbenium route and the alternative $[2+2]$-cycloaddition based pathway. It is found that the $[2+2]$-pathway is disfavored for those alcohols having non-activated and non-substituted alkenes. In these cases, the classical pathway via the key oxocarbenium ion is preferred. In addition, the final products distribution strongly depends upon the nature of the substituent adjacent to the hydroxyl group in the homoallylic alcohol which can favor or hamper a side 2-oxonia-Cope rearrangement
\end{abstract}

\section{Introduction}

Tetrahydropyrans (THPs) are common structural units present and widespread in many natural products, ${ }^{[1]}$ from marine natural products such as brevetoxin B or gambierol to biological active macrolides and macrolactones such as dactylolide and bryostatin 1, respectively (Figure 1)..$^{[2,3]}$ Therefore, THP derivatives represent a very attractive targets for synthetic organic chemists. Among the different methods and strategies to synthetize THP rings, ${ }^{[4]}$ the so-called Prins cyclization reaction has emerged as a powerful tool allowing the efficient access to these oxacycles. For this reason, it is not surprising that this process has been widely applied to the synthesis of natural products. ${ }^{[5]}$ This cyclization is based on the reaction between a homoallylic alcohol or derivative with aldehydes promoted or catalyzed by Brønsted as well as Lewis acids (Scheme 1). ${ }^{[6]}$ The keystone in the widely accepted mechanism is the generation of an oxocarbenium ion which drives the cyclization. However, this species can also experience an oxonia-Cope rearrangement as a competitive pathway, leading to

[a] S. J. Pérez, Dr. M. Purino, Prof. V. S. Martín, Dr. J. I. Padrón Instituto Universitario de Bio-Orgánica "Antonio González" Universidad de La Laguna

C/Francisco Sánchez 2, 38206, La Laguna, Tenerife (Spain)

Fax: (+) 34922318571

E-mail:vmartin@ull.es

[b] Dr. I. Fernández

Departamento de Química Orgánica

Facultad de Ciencias Químicas, Universidad Complutense de Madrid

28040 Madrid (Spain)

E-mail: israel@quim.ucm.es

[c] Dr. P. O. Miranda, Dr. J. I. Padrón

Instituto de Productos Naturales y Agrobiología

Consejo Superior de Investigaciones Científicas (CSIC)

C/Francisco Sánchez 3, 38206, La Laguna, Tenerife (Spain)

Fax: (+) 34922260135

E-mail: jipadron@ipna.csic.es

Supporting information for this article is available on the WWW under http://www.chemeurj.org/ or from the author. two deleterious problems, namely a mixture of products by sidechain exchange and racemization. These processes have been deeply studied by the groups of Rychnovsky and Willis. ${ }^{[7]}$
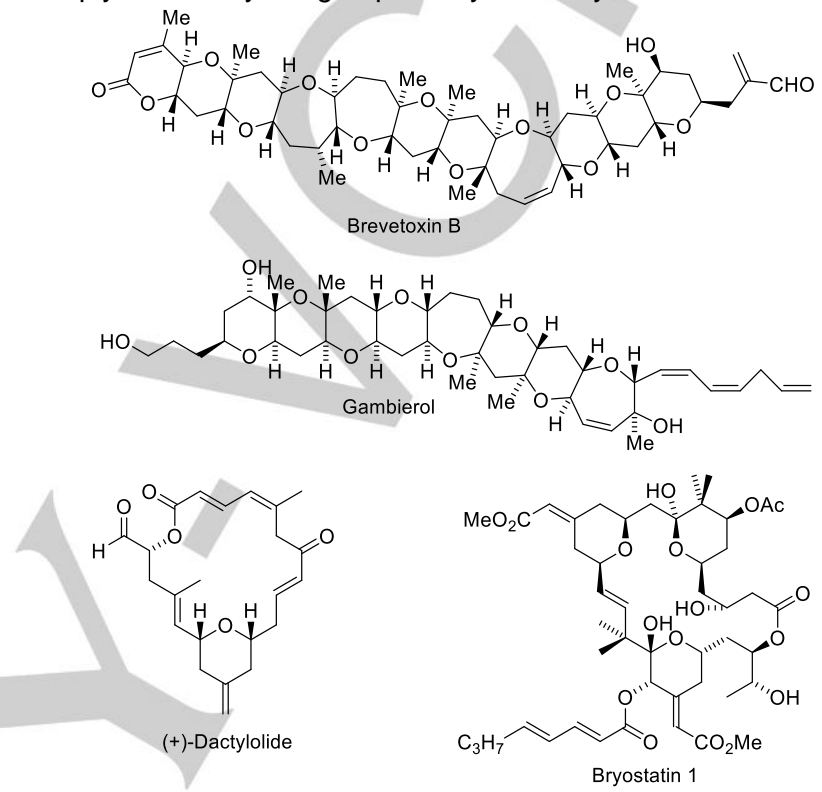

Figure 1. Selected examples of natural products containing tetrahydropyrans as subunits.

From the very beginning, this cyclization was promoted using strongly acidic conditions in stoichiometric amounts and mixed acetals as starting materials. This strategy ensured the mechanistic pathway through an oxocarbenium intermediate as the unique alternative. ${ }^{[7,8]}$ At variance, many different Lewis acids have been recently used in the synthesis of substituted tetrahydropyrans with different substitution at the C-4 position, i.e. halogen, ${ }^{[9]}$ and hydroxyl moieties. ${ }^{[6,10]}$ Strikingly, the combination of substoichiometric amounts of Lewis acid with trimethylsilyl halide (TMSX) led to a highlighted improvement of this cyclization reaction. Loh and co-workers have applied the combination of indium salts and chlorotrimethylsilane (TMSCl) as catalyst to the synthesis of 4-halo- tetrahydropyran rings. ${ }^{[11]}$ Later on, the combination of TMSX with iron(III) salts $\left(\mathrm{FeX}_{3}\right.$ and $\left.\mathrm{Fe}(\mathrm{acac})_{3}\right)$ permitted us to catalyze the Prins cyclization using non-activated alkenes and alkynes in a sustainable metal catalysis context (Scheme 1). ${ }^{[12]}$

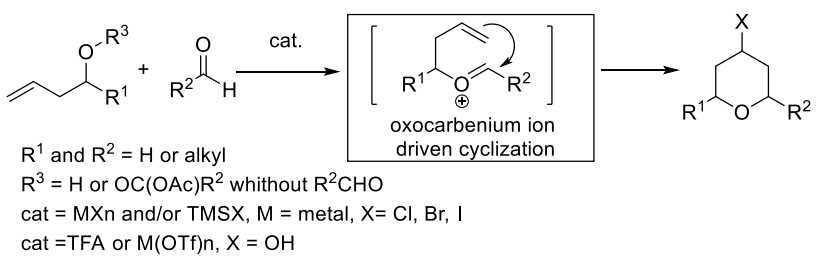

Scheme 1. Oxocarbenium ion drives Prins cyclization. 
This catalytic system is widely applicable and promotes the construction of substituted six-membered oxa- and azacycles, leading to the corresponding chloro, bromo and iodo heterocycles by the suitable combination of an iron(III) source, a trimethylsilyl halide and the solvent. The devised catalytic cycle relies on a ligand exchange between the iron complex and a halosilane, which regenerates the iron(III) halide due to the more oxophilic character of the silicon atom. This system presents several advantages such as the use of reduced amounts of metal, tolerance of functional groups present in the aldehyde, and cleaner reactions. Using this methodology, the synthesis of enantiomerically pure 4-hydroxyl-tetrahydropyran derivatives was successfully accomplished by Feng and co-workers recently, in an excellent study, through a sequential ene/Prins cyclization using $\mathrm{FeCl}_{3} / \mathrm{TBSCl}$ as a catalyst. ${ }^{[6 t]}$

Herein, we describe the different factors that control the alkene Prins cyclization catalyzed by iron(III) salts in the presence of $\mathrm{SiMe}_{3} \mathrm{X}(\mathrm{X}=\mathrm{Cl}, \mathrm{Br})$ towards the synthesis of crossed disubstituted tetrahydropyrans. Density Functional Theory (DFT) calculations supports the preference of classical oxocarbenium ion pathway over the possible [2+2] pathway and explains the origin of the observed product distribution, which depends on the nature of the substituent at the homoallylic alcohol and the iron(III) source.

\section{Results and Discussion}

Influence of the oxonia-cope rearrangement in the alkenePrins cyclization using the catalytic system Fe(III)/TMSX

As commented above, the Prins cyclization mechanism is based on the generation of an oxocarbenium ion intermediate $\mathbf{2}$ which drives the formation of the corresponding tetrahydropyrans (Scheme 2). However, this cationic intermediate may also undergo an oxonia-Cope rearrangement to generate a new homoallylic alcohol $\left(\mathbf{1}^{*}\right)$ and an aldehyde that can participate in a new Prins cyclization process thus generating the undesired species 3 and $\mathbf{5}$, besides the tetrahydropyran 4 (Scheme 2). Furthermore, due to the involvement of an oxocarbenium ion, a mixture of diastereoisomers would be expected. Therefore, it was necessary to carry out a study on the influence of the oxonia-Cope rearrangement on the tetrahydropyrans distribution as well as their possible consequences using non-activated alkenes.

In a preliminary work, and using stoichiometric amounts of iron(III) chloride, we observed that the distribution of tetrahydropyrans mainly depends on two factors, namely the bulkiness of the substituent group at $R^{1}$ and the electronic effect of the substituents directly attached to the aromatic ring at $R^{1}$. An increment of the bulkiness of $R^{1}$ group (methyl, ethyl and cyclohexyl) increased the formation of the desired THP $\mathbf{4}$ with a subsequent decrease of THP 5 . This steric control therefore favored the Prins cyclization to $\mathbf{4}$ over the 2-oxonia-Cope rearrangement. Moreover, when $R^{1}$ is an aromatic ring the presence of electron-deficient substituents favors the Prins cyclization yielding the THP $\mathbf{4}$ as the major product. ${ }^{[13]}$

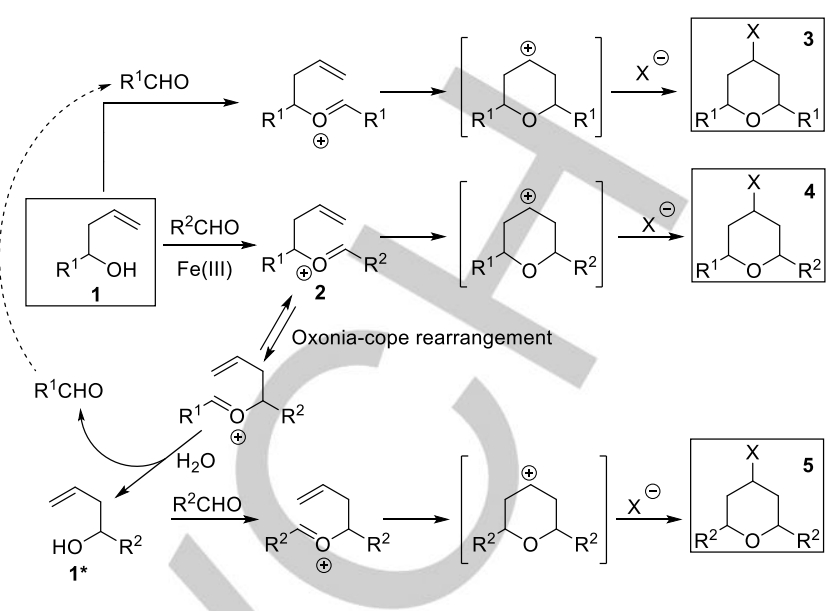

Scheme 2. Possible mixture of tetrahydropyrans in the Prins cyclization by participation of oxonia-Cope rearrangement.

In order to have a better understanding of the effect of the catalytic system on the competitive processes (Prins cyclization vs oxonia-Cope rearrangement), different sources of $\mathrm{Fe}$ (III) salts as well as TMSX were evaluated. Moreover, these results, which are summarized in Table 1, can be compared to our previous studies using stoichiometric amounts of $\mathrm{FeCl}_{3} \cdot{ }^{[13]}$

When $\mathrm{R}^{1}$ is a phenyl ring and $\mathrm{R}^{2}$ an $i$-butyl group, the cyclization under stoichiometric conditions leads to a 50:50 mixture of tetrahydropyrans 4 and 5 in $70 \%$ yield. ${ }^{[13]}$ We focused on this particular case as a starting point of our comparative study. In the case of allyl phenyl carbinol $\mathbf{1}\left(\mathrm{R}^{1}=\mathrm{Ph}\right)$ the percentage of the desired THP 4 was improved to $87 \%$ under catalytic conditions, being not necessary the presence of electron-deficient substituents (Table 1, entry 1). ${ }^{[7 a]}$ This is a remarkable result because Willis and co-workers had to introduce an electrondeficient substituent on the aromatic ring and use stoichiometric amounts of Lewis acid to obtain the same products distribution. [7a] The cyclization works well with both iron(III) salts, $\mathrm{FeCl}_{3}$ and $\mathrm{Fe}(\mathrm{acac})_{3}$, leading to similar reaction yields. The combination of these conditions with a bulkier group at $\mathrm{R}^{2}(c-\mathrm{Hex})$ results in a slight increase of the percentage of THP-4 up to $89 \%$ (Table 1, entry 2). With homobenzyl as substituent at $R^{1}$, the crossed 4chloro-2,6-trisubstituted THP 4 was obtained almost exclusively, minimizing the competitive 2-oxonia-Cope rearrangement and side-chain exchange (Table 1, entry 3 ). ${ }^{[14]}$ The best results were obtained when combining $n$-hexyl and $i$-butyl as $\mathrm{R}^{1}$ with $c$-hexyl as $R^{2}$ (Table 1, entries 5 and 7). In these cases, the crossed THP4 was obtained exclusively with excellent yields. Similar results were obtained in the bromo-version of the catalytic system (Table 1, entries 8-12). The best ratios of crossed 4-bromo-2,6trisubstituted THP 4 were obtained with $c$-hexyl as $R^{2}$ and $\mathrm{Fe}(\mathrm{acac})_{3}$ as iron(III) source (Table 1, entries 10 and 12). The nature of silyl additive does not influence either the ratio or the yield of the Prins cyclization catalyzed by iron(III). ${ }^{[15]}$

At this moment, the combination of catalytic amounts of iron(III) salts and $\mathrm{TMSCl}$ as additive is effective and nearly cancels the 2-oxonia-Cope rearrangement favoring the direct Prins cyclization under the specified experimental conditions. We 
have therefore solved some of the side reactions, avoiding the exchange of aldehyde and alcohol side chains.

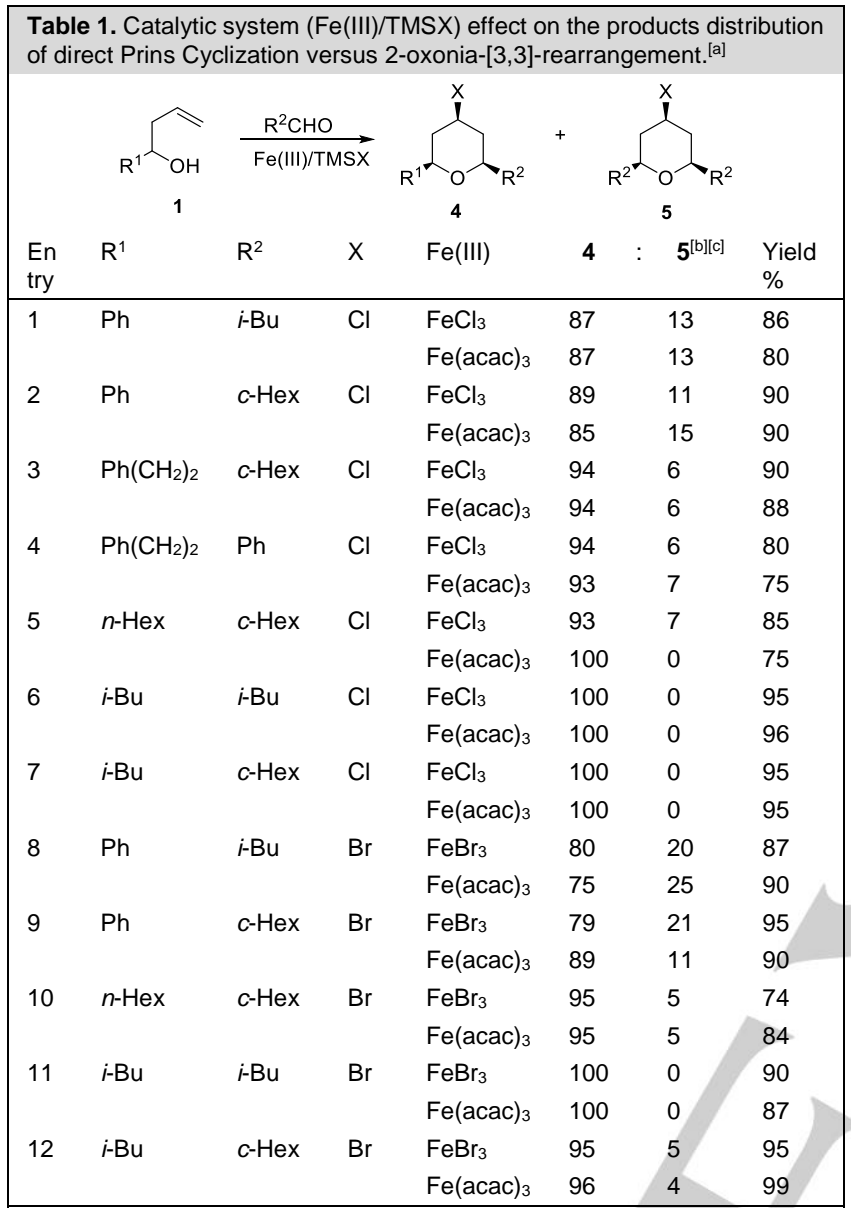

[a] reactions conditions: 1 (1.0 mmol), $\mathrm{R}_{2} \mathrm{CHO}(1.2 \mathrm{mmol})$ and $\mathrm{Fe}(\mathrm{III})(0.1$ $\mathrm{mmol} / \mathrm{TMSX}(1.1 \mathrm{mmol})$ in dry $\mathrm{CH}_{2} \mathrm{Cl}_{2}(10 \mathrm{~mL})$ at $\mathrm{rt}$ for $15 \mathrm{~h}$. [b] Yields of products after purification by silica gel column chromatography. [c] We did not observe any THP 3 product.

\section{Theoretical calculations on Iron(III)-catalyzed alkene-Prins cyclization}

Density Functional Theory (DFT) calculations were carried out $\quad\left(\mathrm{PCM}\left(\mathrm{CH}_{2} \mathrm{Cl}_{2}\right)\right.$ B3LYP/def2-TZVP//B3LYP/def2-SVP level $)^{[16,17]}$ to gain more insight into the reaction mechanism of the above iron(III)-catalyzed Prins cyclization reactions. To this end, we have selected the reaction between the model reactants $1\left(R^{1}\right.$ $=\mathrm{Me}$ ) and $\mathrm{MeCHO}$ in the presence of $\mathrm{FeCl}_{3}$ as catalyst.

At this point, it is important to consider the recent work of Feng and co-workers based on labeling as well as DFT studies. ${ }^{[6]]}$ These authors suggest a new mechanism for the $\mathrm{FeCl}_{3}$-catalyzed Prins cyclization between homoallylic alcohols and aldehydes. It was proposed that the entire catalytic cycle proceeds via the following three consecutive steps: (1) initial [2+2] cycloaddition reaction leading to the oxetane intermediate $\mathbf{A},(2)$ nucleophilic attack of the $\mathrm{OH}$ group at the electrophilic $\mathrm{C}-\mathrm{OFeCl}_{3}$ center with concomitant ring opening to form intermediate $\mathbf{B}$, and (3) intramolecular proton transfer to produce compound $\mathbf{C}$ (Scheme
3). Step (2) occurs with an activation barrier of ca. $27 \mathrm{kcal} / \mathrm{mol}$ and constitutes the rate-determining step of the entire transformation. ${ }^{[6]]}$

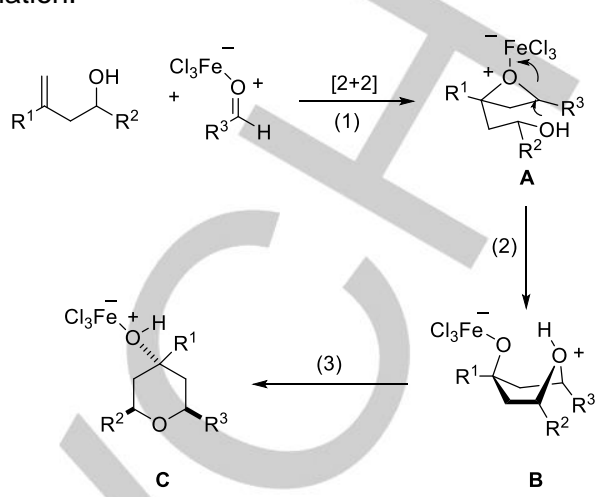

Scheme 3. Feng's mechanistic model for the $\mathrm{FeCl}_{3}$-catalyzed Prins cyclization

This alternative reaction mechanism can be only considered as a special class of the Prins cyclization because of the particular nature of the substrates used by Feng and co-workers. These authors use a homoallylic alcohol with an activated alkene (typically $\mathrm{R}^{1}=$ aromatic) having an ester group as $\mathrm{R}^{2}$, which favors the initial stepwise [2+2]-cycloaddition step (Scheme 3). Feng and co-workers also showed that homoallylic alcohols with 4unsubstituted alkenes but keeping the ester at $R^{2}$ did not produce the Prins cyclization. ${ }^{[6]]}$ Despite that, we were curious to calculate an analogous reaction pathway for our substrates, where $\mathrm{R}^{1}=\mathrm{H}$ and $R^{2} \neq$ ester. From the barrier energies shown in Figure 2 , it seems that the pathway leading to the axial-hydroxyl derivative INT4 (species C, Scheme 3) is feasible from the initially formed oxetane intermediate INT2 (species A, Scheme 3). However, the formation of the latter intermediate is clearly more difficult for systems lacking an aromatic substituent at 4-position relative to the oxygen. Not surprisingly, the computed activation barrier for the second step of the [2+2]-cycloaddition (which produces INT2) is much higher $(29.4 \mathrm{kcal} / \mathrm{mol}$, corresponding free energy of 38.7 $\mathrm{kcal} / \mathrm{mol}$ ) than the analogous process reported by Feng and coworkers $\left(4.7 \mathrm{kcal} / \mathrm{mol}, \mathrm{R}^{1}=\mathrm{Ph}, \mathrm{R}^{2}=\mathrm{CO}_{2} \mathrm{Et}, \mathrm{R}^{3}=\mathrm{Et}\right.$, at the similar $\mathrm{PCM}\left(\mathrm{CH}_{2} \mathrm{Cl}_{2}\right) / / \mathrm{B} 3 \mathrm{LYP} / 6-31 \mathrm{G}^{* *}$ level). ${ }^{[6]]}$ In addition, all our attempts to locate the corresponding carbocationic intermediate INT1 on the potential energy surface (even including the solvent during the geometry optimizations) met with no success, i.e. only dissociation into the initial reactants was found. These results suggest that the [2+2]-cycloaddition is disfavored when using homoallylic alcohols having non-activated and non-substituted alkenes. In the absence of substituents at the double bond (as it occurs in the substrates considered in the present work), this pathway can be ruled out and therefore, the so-called "classical" pathway seems to be operating. Further experimental support to this finding is given by the absence of the corresponding 4hydroxy derivatives from INT4 (no traces of this type of products were observed in the reaction crudes). Moreover, if the [2+2]mechanism were operating, adding 4-hydroxy or 4-TMSO THP (compounds 6 and 7, respectively) would produce the observed 


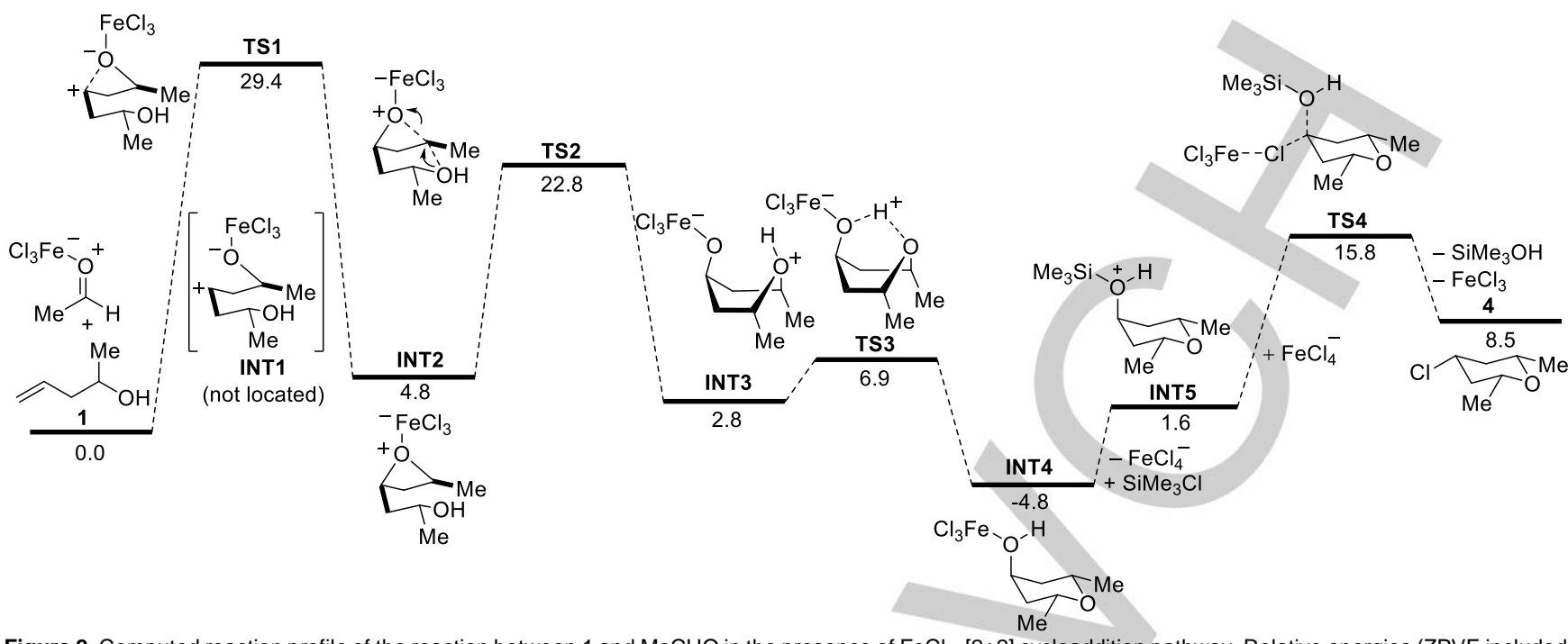

Figure 2. Computed reaction profile of the reaction between 1 and $\mathrm{MeCHO}$ in the presence of $\mathrm{FeCl}_{3}$, [2+2] cycloaddition pathway. Relative energies (ZPVE included) are given in $\mathrm{kcal} / \mathrm{mol}$. All data have been computed at the PCM $\left(\mathrm{CH}_{2} \mathrm{Cl}_{2}\right) \mathrm{B} 3 \mathrm{LYP} / \mathrm{def} 2-\mathrm{TZVP} / / \mathrm{B} 3 \mathrm{LYP} / \mathrm{def} 2-\mathrm{SVP}$ level

4-equatorial chloride 4 product under the same reaction conditions (Scheme 4). However, the latter reaction product 4 was only observed, in very low yield by treatment of the 4-OTMS THP 7 under catalytic conditions (Scheme 4, eq 2).

Therefore, it can be concluded that the [2+2]-pathway does not occur within the substrates and reaction conditions considered in this work. Once the classical pathway is confirmed to be preferred, we then computationally studied the formation of the key oxocarbenium ion 2 (Scheme 2). The computed reaction profile for the reaction between $1\left(R^{1}=\mathrm{Me}\right)$ and the iron(III)-coordinated aldehyde $\mathrm{MeCHO}$ is depicted in Figure 3. Our calculations suggest that the process begins with the coordination of the initial reactants to the $\mathrm{FeCl}_{3}$ to form INT6. This complex is stabilized by an intramolecular $\mathrm{Cl} \ldots \mathrm{HO}$ hydrogen bond which weakens the corresponding $\mathrm{Fe}-\mathrm{Cl}$ bond. As a result, a molecule of $\mathrm{HCl}$ can be released to produce INT7 in an endothermic process $(\Delta E=14.8$ $\mathrm{kcal} / \mathrm{mol}$ ). This intermediate is transformed into the metalla-1,3dioxetane INT8 through the transition state TS5, a saddle point associated with the formation of the new $\mathrm{C}-\mathrm{O}$ bond, with an activation barrier of $12.5 \mathrm{kcal} / \mathrm{mol}$. INT8 evolves then into INT9 via TS6, a transition state associated with the protonolysis of the $\mathrm{Fe}-$ $\mathrm{O}$ promoted by $\mathrm{HCl}$. The ease of the latter reaction step is confirmed by the low computed activation barrier $\left(\Delta E^{\neq}=6.2\right.$ $\mathrm{kcal} / \mathrm{mol})$ and high exothermicity $(\Delta E=-16.0 \mathrm{kcal} / \mathrm{mol})$. It can be suggested that INT9 is then converted into INT10 in a slightly endothermic reaction $(\Delta E=3.2 \mathrm{kcal} / \mathrm{mol})$. This reaction very likely proceeds via decoordination of the $\mathrm{FeCl}_{3}$ catalyst followed by nucleophilic substitution reaction between the readily formed alcohol and $\mathrm{SiMe}_{3} \mathrm{Cl}$ to produce the cation INT10 and $\mathrm{FeCl}_{4}{ }^{-}$as counteranion. We were not able to locate a transition state associated with the intramolecular nucleophilic addition of the $\mathrm{C}=\mathrm{C}$ double bond with concomitant release of $\mathrm{SiMe}_{3} \mathrm{OH}$ in INT10. Instead, we found a $S_{N} 1$-type mechanism which involves the initial release of the $\mathrm{SiMe}_{3} \mathrm{OH}$ fragment to produce the cationic intermediate INT11. This step is highly exothermic $(\Delta E=-14.9$ $\mathrm{kcal} / \mathrm{mol}$ ) as a result of the stabilization of the carbocation by the adjacent oxygen atom. Then, the intramolecular cyclization reaction occurs via TS7, which is associated with the formation of the new $\mathrm{C}-\mathrm{C}$ bond with an activation barrier of only $6.8 \mathrm{kcal} / \mathrm{mol}$. This process leads to the formation of INT12, in which both methyl substituents are placed in equatorial positions. The geometry of this carbocation directs the subsequent nucleophilic attack, either by $\mathrm{FeCl}_{4}{ }^{-}$or simply by $\mathrm{Cl}^{-}$, from the equatorial position as the axial delivery is sterically hampered (see inset in Figure 3).

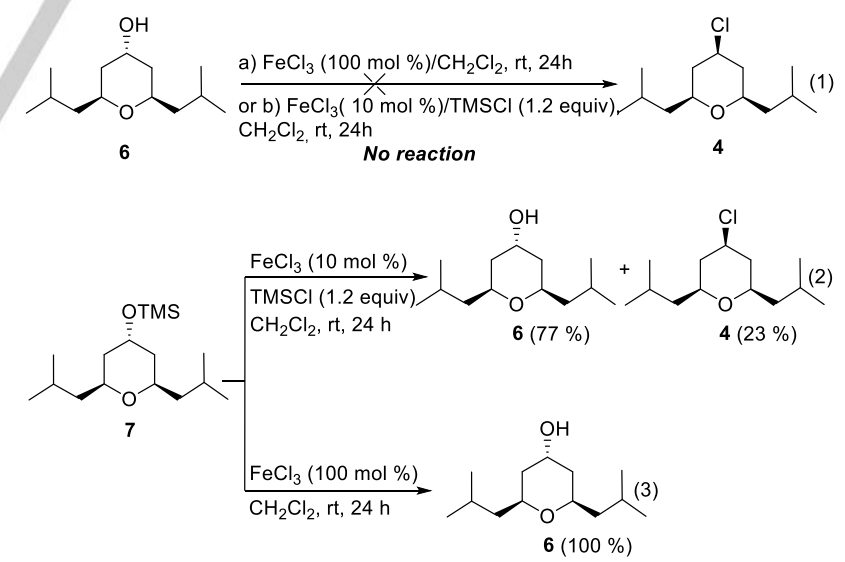

Scheme 4. Control experiments in the plausible hydroxy intermediates of the $[2+2]$ cycloaddition pathway.

From the data in Figure 3, the initial $\mathrm{C}-\mathrm{O}$ bond formation and subsequent $\mathrm{Fe}-\mathrm{O}$ protonolysis constitute the ratedetermining steps of the entire transformation. In addition, the overall relative reaction profile for this classical oxocarbeniumpathway is energetically favored over the alternative [2+2]pathway (see Figure 2), which nicely agrees with the experimental observations. 


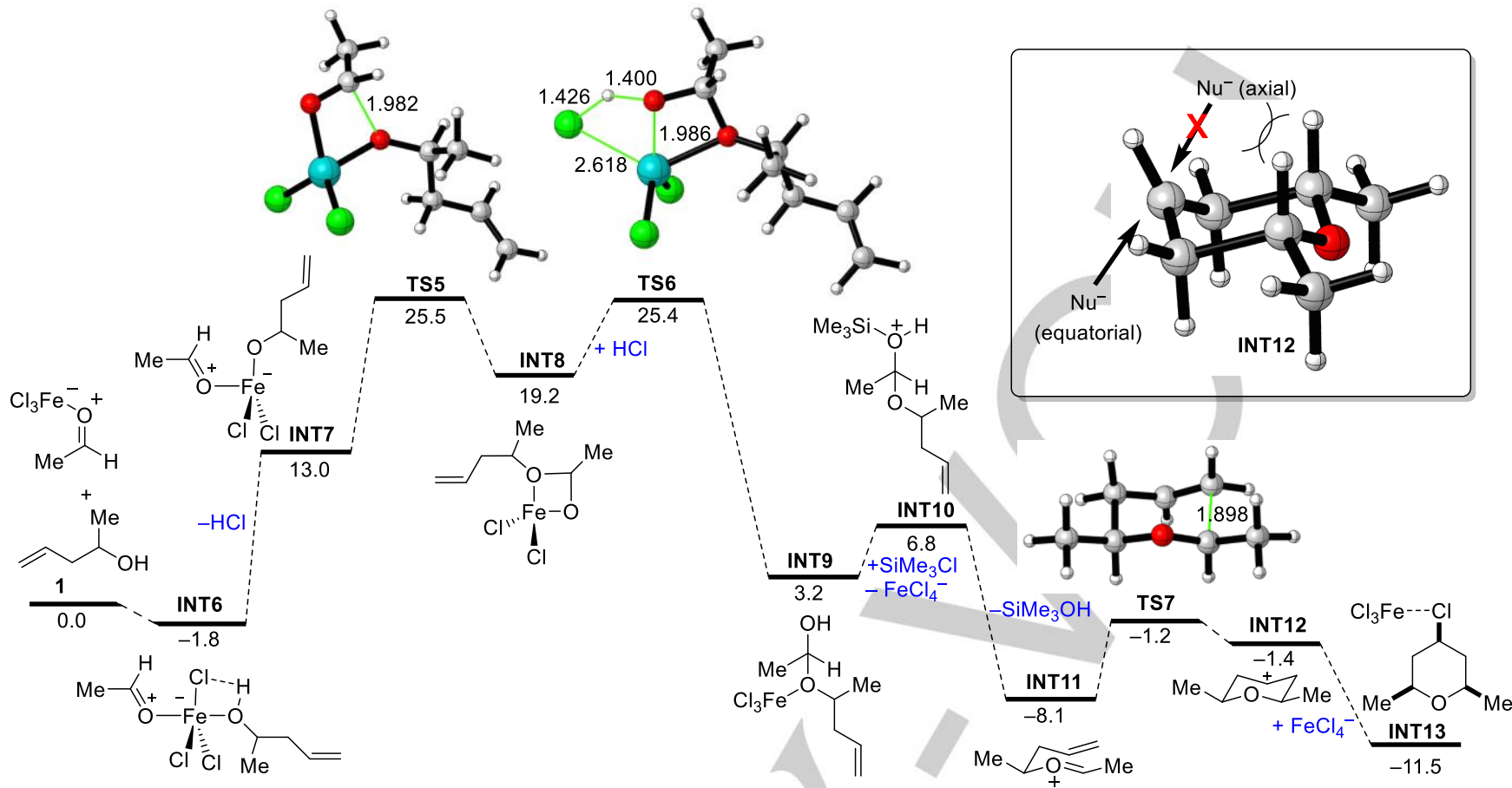

Figure 3. Computed reaction profile of the reaction between 1 and $\mathrm{MeCHO}$ in the presence of $\mathrm{FeCl}_{3}$ and $\mathrm{SiMe}_{3} \mathrm{Cl}$, oxocarbenium ion pathway. Relative energies (ZPVE included) are given in $\mathrm{kcal} / \mathrm{mol}$ and bond distances in angstroms. All data have been computed at the $\mathrm{PCM}\left(\mathrm{CH}_{2} \mathrm{Cl} \mathrm{L}_{2}\right) \mathrm{B} 3 \mathrm{LYP} / \mathrm{def} 2-\mathrm{TZVP} / / \mathrm{B} 3 \mathrm{LYP} / \mathrm{def2}-\mathrm{SVP}$ level.

The occurrence of mixture of products $(3,4$ and 5 , Scheme 2) by means of competitive 2-oxonia-Cope rearrangement and side-exchange reaction is fully compatible with the above described classical pathway via the key oxocarbenium ion. Despite that, the final product distribution strongly depends on the experimental conditions, type of alkene and iron(III) salts. For instance, we observed significant differences when using stoichiometric instead of catalytic conditions. Thus, the relative amount of $\mathbf{5}$ is in general higher under stoichiometric amounts of iron(III) salts than under catalytic conditions. Moreover, acetal $\mathbf{8}$, which contributes to the oxocarbenium ion formation $\mathbf{9}$, is only present under stoichiometric conditions (Scheme 5).

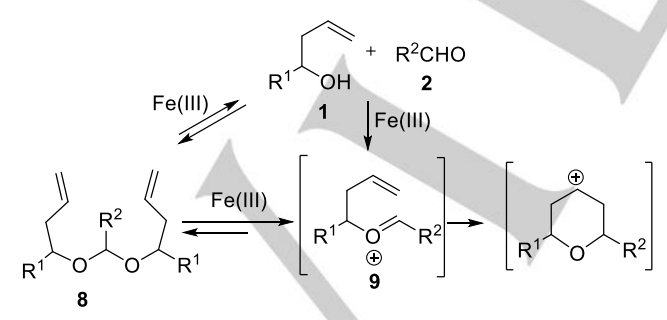

Scheme 5. Contribution of the acetal to the oxocarbenium ion pathway.

Both the iron ligand and the reaction temperature have also a direct effect on the tetrahydropyran distribution when the homoallylic alcohol $\mathbf{1}$ bears at $\mathrm{R}^{1}$ a phenyl group (Table 2). For instance, with $\mathrm{Fe}(\mathrm{OTf})_{3} / \mathrm{TMSCl}$ as catalytic system, the decrease of the amount of THP 4 involves the increase of the amounts of THPs 5 and 3, the latter being observed for the first time (Table 2, entry 3$)$.

Table 2. Iron ligand and temperature effect on the ratio of direct Prins Cyclization versus product derived from the 2-oxonia-[3,3]-rearrangement. ${ }^{[a]}$

\begin{tabular}{|c|c|c|c|c|c|c|c|c|}
\hline & 1 & $\frac{\mathrm{R}^{2} \mathrm{CH}}{\mathrm{Fe}(\mathrm{III}) /}$ & & 4 & 5 & & 3 & \\
\hline Entry & $\mathrm{R}^{1}$ & $\mathrm{R}^{2}$ & Temp. & $\mathrm{FeL}_{3}$ & 4 & 5 & $3^{[b]}$ & $\begin{array}{l}\text { Yield } \\
\%\end{array}$ \\
\hline 1 & $i$-Bu & $i$-Bu & it & $\mathrm{Fe}(\mathrm{OTf})_{3}$ & 100 & 0 & 0 & 90 \\
\hline 2 & $i$-Bu & $c$-Hex & rt & $\mathrm{Fe}(\mathrm{OTf})_{3}$ & 100 & 0 & 0 & $>99$ \\
\hline 3 & $\mathrm{Ph}$ & $i$-Bu & $\mathrm{rt}$ & $\mathrm{Fe}(\mathrm{OTf})_{3}$ & 30 & 45 & 25 & 74 \\
\hline 4 & $\mathrm{Ph}$ & $i-\mathrm{Bu}$ & $0^{\circ} \mathrm{C}$ & $\mathrm{FeCl}_{3}$ & 22 & 59 & 19 & 75 \\
\hline 5 & $\mathrm{Ph}$ & $i$-Bu & $0 \stackrel{\circ}{ } \mathrm{C}$ & $\mathrm{Fe}(\mathrm{acac})_{3}$ & 23 & 62 & 15 & 87 \\
\hline 6 & $\mathrm{Ph}$ & $i$-Bu & $0 \stackrel{\circ}{ } \mathrm{C}$ & $\mathrm{Fe}(\mathrm{OTf})_{3}$ & 15 & 85 & 0 & 75 \\
\hline 7 & $i$-Bu & $c$-Hex & $0 \stackrel{\circ}{ } \mathrm{C}$ & $\mathrm{FeCl}_{3}$ & 100 & 0 & 0 & 80 \\
\hline 8 & $i$-Bu & $c$-Hex & $0^{\circ} \mathrm{C}$ & $\mathrm{Fe}(\mathrm{acac})_{3}$ & 100 & 0 & 0 & 84 \\
\hline 9 & $i-\mathrm{Bu}$ & $c$-Hex & $0 \stackrel{\circ}{ } \mathrm{C}$ & $\mathrm{Fe}(\mathrm{OTf})_{3}$ & 100 & 0 & 0 & 73 \\
\hline 10 & $\mathrm{Ph}$ & $i$-Bu & $40^{\circ} \mathrm{C}$ & $\mathrm{FeCl}_{3}$ & 10 & 90 & 0 & 80 \\
\hline 11 & $\mathrm{Ph}$ & $i-\mathrm{Bu}$ & $40^{\circ} \mathrm{C}$ & $\mathrm{Fe}(\mathrm{acac})_{3}$ & 25 & 75 & 0 & 75 \\
\hline 12 & $\mathrm{Ph}$ & $i$-Bu & $40 \stackrel{\circ}{C}$ & $\mathrm{Fe}(\mathrm{OTf})_{3}$ & 28 & 57 & 14 & 64 \\
\hline 13 & $i$-Bu & $c$-Hex & $40^{\circ} \mathrm{C}$ & $\mathrm{FeCl}_{3}$ & 100 & 0 & 0 & $>99$ \\
\hline 14 & $i$-Bu & $c$-Hex & $40^{\circ} \mathrm{C}$ & $\mathrm{Fe}(\mathrm{acac})_{3}$ & 100 & 0 & 0 & 95 \\
\hline 15 & $i$-Bu & $c$-Hex & $40^{\circ} \mathrm{C}$ & $\mathrm{Fe}(\mathrm{OTf})_{3}$ & 100 & 0 & 0 & $>99$ \\
\hline
\end{tabular}

[a] reactions conditions: $1(1.0 \mathrm{mmol}), \mathrm{R}^{2} \mathrm{CHO}(1.2 \mathrm{mmol})$ and $\mathrm{Fe}(\mathrm{III})(0.1$ $\mathrm{mmol} / \mathrm{TMSCl}(1.1 \mathrm{mmol})$ in dry $\mathrm{CH}_{2} \mathrm{Cl}_{2}(10 \mathrm{~mL})$ at rt for $15 \mathrm{~h}$ and $24 \mathrm{~h}$ at $0 \circ \mathrm{C}$. [b] Yields of products after purification by silica gel column chromatography. 
Similar results are obtained when using allyl phenyl carbinol $\left(\mathbf{1}, \mathrm{R}^{1}=\mathrm{Ph}\right)$ and a reaction temperature of $0^{\circ} \mathrm{C}$. In this case, we obtained a mixture of THPs $\mathbf{3}, \mathbf{4}$ and 5 regardless of the iron(III) salt used (Table 2, entries 4-6). ${ }^{[18]}$ When using Fe(OTf) ${ }_{3}$ the major compound is the THP 5 (Table 2, entry 6). This behavior was also observed when changing the temperature of the reaction to $40^{\circ} \mathrm{C}$ (Table 2, entries 10-12). However, when the homoallylic alcohol 1 bears an aliphatic substituent, the Prins cyclization leads exclusively to the THP 4 regardless of the reaction temperature or iron ligands (Table 2, entries 1-2, 7-9 and 13-15).

From all this data in Table 2, it becomes clear that the oxonia-Cope rearrangement is favored when using allyl phenyl carbinols, triflate as iron ligand and modifying the temperature of the cyclization.

At this point, we tried to rationalize the finding of the formation of the mixture of THPs when $\mathrm{R}^{1}=\mathrm{Ph}$. To this end, we decided to carry out a theoretical study comparing the oxoniaCope rearrangement with phenyl and iso-butyl as $\mathrm{R}^{1}$ substituents (Figure 4). Although the computed activation barrier is quite similar in both cases $\left(\Delta \Delta E^{\neq}\right.$of only $\left.0.2 \mathrm{kcal} / \mathrm{mol}\right)$, the process is greatly thermodynamically favored $(\Delta \Delta E=9.3 \mathrm{kcal} / \mathrm{mol})$ for the oxocarbenium ion having a phenyl substituent (2-Ph, Figure 4). This can be of course ascribed to the stabilization by $\pi$ conjugation exerted by the phenyl group in 2'-Ph, which constitutes the driven force for the rearrangement. At variance, the stabilization by hyperconjugation exerted by the isobutyl group is comparatively much weaker, making the rearrangement much more difficult (i.e. 2'-iBu is practically isoenergetic to 2-iBu, which suggests an equilibrium between both species). Therefore, our computational data indicate that the oxonia-Cope rearrangement is favored when $\mathrm{R}^{1}=\mathrm{Ph}$, which is in agreement with the experimental results gathered in Table 2.
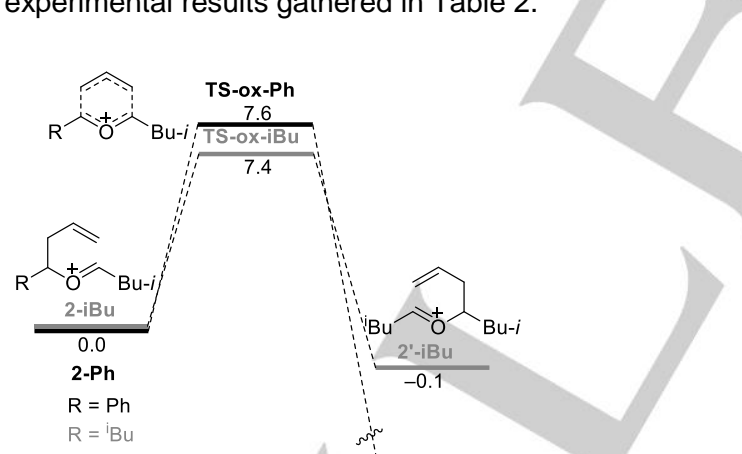

Figure 4. A comparative computed reaction profile for the oxonia-Cope rearrangement with phenyl and alkyl as $R^{1}$ substituents. Relative energies (ZPVE included) are given in $\mathrm{kcal} / \mathrm{mol}$. All data have been computed at the $\mathrm{PCM}\left(\mathrm{CH}_{2} \mathrm{Cl}_{2}\right) \mathrm{B} 3 \mathrm{LYP} /$ def2-TZVP//B3LYP/def2-SVP level.

Finally, racemization in the Prins cyclization has been also suggested to be an indicator for the participation of the oxoniaCope rearrangement in the process. ${ }^{[7]}$ Thus, the next step was to check the level of racemization in the process under our catalytic conditions that, in principle, should be low based on the data commented above on Table 1. For this purpose, we carried out the Prins cyclization between alcohol $(R)-\mathbf{1}$ and benzaldehyde using our catalytic system (Scheme 6 ). The use of $10 \mathrm{~mol} \%$ of $\mathrm{FeCl}_{3}$ yielded the desired product 8 with a $96 \%$ ee, which nicely indicates that no competitive 2-oxonia-Cope rearrangement or side-chain exchanged occurred.

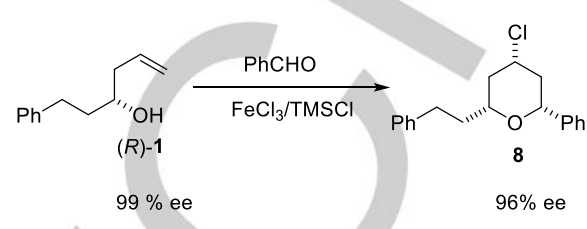

Scheme 6. Iron(III) salt/TMSCl system catalyzes Prins cyclization preventing racemization.

\section{Conclusions}

We have established a method to obtain almost exclusively crossed 2,4,6-trisubstituted tetrahydropyrans by using the catalytic system iron(III) salts and TMSX and avoiding side-chain exchange and racemization processes. In this iron(III)-catalyzed Prins cyclization reaction between homoallylic alcohols with nonactivated alkenes two mechanistic pathways can be envisaged, namely the classical oxocarbenium route and the alternative [2+2]-cycloaddition based pathway. Our joint experimental and computational study clearly confirms that the [2+2]-pathway is disfavored for those alcohols having non-activated and nonsubstituted alkenes. In these cases, the classical pathway via the key oxocarbenium ion $\mathbf{2}$ is preferred. Furthermore, the nature of the substituent adjacent to the hydroxyl group in the homoallylic alcohol is decisive to control the possible oxonia-Cope rearrangement of the corresponding oxocarbenium ion. Thus, whereas alkyl substituents do not favor this side-rearrangement and therefore, lead almost exclusively to crossed tetrahydropyran derivatives, the 2-oxonia-Cope rearrangement is strongly thermodynamically favored in the presence of a phenyl group. As a result, a mixture of tetrahydropyrans is observed in these cases.

\section{Experimental Section}

General methods and computational details are given in the Supporting Information.

General procedure by the iron(III) salt/TMSX catalyzed Prins cyclization: To a solution of homoallylic alcohol (1.0 equiv) in anhydrous $\mathrm{CH}_{2} \mathrm{Cl}_{2}(0.1 \mathrm{M})$ was added the corresponding aldehyde (1.2 equiv) and then the iron(III) salt ( 0.1 equiv) and TMSX ( 1.1 equiv) in this order. The reaction mixture was stirred at room temperature for $15 \mathrm{~h}$. The reaction was quenched by addition of water with stirring for $90 \mathrm{~min}$, and the mixture extracted with $\mathrm{CH}_{2} \mathrm{Cl}_{2}$. The combined organic layers were dried over magnesium sulphate, filtered and the solvent was removed under reduced pressure. This crude reaction mixture was purified by flash silica gel column chromatography ( $n$-hexane/EtOAc solvent systems). 


\section{Acknowledgements}

We first thank the referees of this work for several suggestions which strengthened the manuscript. This research was supported by the Spanish MINECO, co-financed by the European Regional Development Fund (ERDF) and FEDER (CTQ2011-28417-C0201/BQU, CTQ2014-56362-C2-1-P, CTQ2011-22653, CTQ201344303-P) and IMBRAIN project (FP7-REGPOT-2012-CT201231637-IMBRAIN), funded under the $7^{\text {th }}$ Framework Programme (CAPACITIES). S.J.P. thanks the Spanish MINECO for a F.P.U fellowship. The research leading to these results has received funding from the People Programme (Marie Curie Actions) of the European Union's Seventh Framework Programme FP7/20072013/ under REA grant agreement $n^{\circ}$ [623155] (P.O.M). The ORFEO-CINQA network is also acknowledged.

Keywords: cyclization $•$ heterocycle $\bullet$ iron $•$ Lewis catalysis • DFT calculations

[1] Selected reviews: a) N. Li, Z. Shi, Y. Tang, J. Chen, X. Li, Beisltein J. Org. Chem. 2008, 4, № 48; b) B. G. Wang, J. B. Gloer, N. Y. Ji, J. C. Zhao, Chem. Rev. 2013, 113, 3632-3685.

[2] a) J. C. Morris, A. J. Phillips, Natural Product Reports 2011, 28, 269-289, and previous issues in the series; b) D. Baden, K. Rein, L. Fieber, S Parker, Patent US20050124685 A1, 2005.

[3] a) K. J. Hale, M. G. Hummersone, S. Manviazar, M. Frigerio. Nat. Prod. Rep. 2002, 19, 413-453; b) P. A. Wender, J. L. Baryza, M. K. Hilinski, J. C. Horan, C. Kan, V. A. Verma. Beyond Natural Products: Synthetic Analogues of Bryostatin 1. In Drug Discovery research: New Frontiers in the Post-Genomic Era; Z. Huang, Ed. Wilyey-VCH: Hoboken, NJ, 2007, pp 127-162; c) A. E. Wright, J. C. Botelho, E. GuzmHn, D. Harmody, P Linley, P. J. McCarthy, T. P. Pitts, S. A. Pomponi, J. K. Reed, J. Nat. Prod. 2007, 70, 412-416; d) A. Cutignano, I. Bruno, G. Bifulco, A. Casapullo, C. Debitus, L. Gómez-Paloma, R. Riccio, Eur. J. Org. Chem. 2001, 775-778; e) G. R. Pettit, C. L. Herald, D. L. Doubek, D. L. Herald, E. Arnold, J. Clardy, J. Am. Chem. Soc., 1982, 104, 6846-6848.

[4] a) T. L. B. Boivin, Tetrahedron 1987, 43, 3309-3362; b) P. A. Clarke, S Santos. Eur. J. Org. Chem. 2006, 2045-2053; c) I. Larrosa, P. Romea F. Urpí, Tetrahedron 2008, 64, 2683-2723; d) J. Muzart, J. Mol. Catal. A: Chem. 2010, 319, 1-29; d) T. Martín, J. I. Padrón, V. S. Martín, Synlett 2014, 25, 12-32.

[5] a) D. L Aubele, S. Wan, P. E. Floreancig, Angew. Chem. Int. Ed. 2005 44, 3485-3488; b) S. K. Woo, M. S. Kwon, E Lee, Angew Chem Int Ed. 2008, 47, 3242-3244; c) P. A. Wender, B. A. DeChristopher, A. J. Schrier, J. Am. Chem. Soc. 2008,130, 6658-6659; d) D. K. Mohapatra P. P. Das, M. R. Pattanayak, J. S. Yadav, Chem. Eur. J. 2010, 16, 2072 2078; e) B. Lin, Y.-C. Lai, Y. Zhao, Y. H. Wong, Z.-L. Shen, T. P. Loh, Angew. Chem. Int. Ed. 2012, 51, 10619-10623, f) X. Han, G.-R. Peh, P. E. Floreancig, Eur. J. Org. Chem. 2013, 1193-1208.

[6] a) E. Arundale, L. A. Mikeska, Chem. Rev. 1952, 51, 505-555; b) I. M. Pastor, M. Yus, Curr. Org. Chem. 2007, 11, 925-927; c) C. Olier, M. Kaafarani, S. Gastaldi, M P. Bertrand, Tetrahedron 2010, 66, 413-445; d) E. A. Crane, K. A. Scheidt, Angew. Chem. Int. Ed. 2010, 49, 8316-
8326; e) I. M. Pastor, M. Yus, Curr. Org. Chem. 2012, 16, 1277-1312; f K. Zheng, X. Liu, S. Qin, M. Xie, L. Lin, C. Hu, X. Feng, J. Am. Chem. Soc. 2012, 134,17564-17573; g) S. J. Greco, G. Fiorot, V. Lacerda, R. B. dos Santos, Aldrichim. Acta 2013, 46, 59-67.

[7] a) S. R. Crosby, J. R. Harding, C. D. King, G. D. Parker, C. L. Willis, Org Lett. 2002, 4, 577-580; b) C. S. Barry, N. Bushby, J. R. Harding, R. A. Hughes, G. D. Parker, R. Roe, C. L. Willis, Chem. Commun. 2005, 3727 3729 ; c) S. Marumoto, J. J. Jaber, J. P. Vitale, S. D. Rychnovsky, Org Lett. 2002, 4, 3919-3922, d) R. Jasti, S. D. Rychnovsky, J. Am. Chem. Soc. 2006, 128, 13640-13648.

[8] a) R. C. Winstead, T. H. Simpson, G. A. Lock, M. D. Schiavelli, D. W. Thompson, J. Org. Chem. 1986, 51, 277-279; b) L. E. Overman, A Castañeda, T. A. Blumenkopf, J. Am. Chem. Soc. 1986, 108, 130311304.

[9] a) Y. Kishi, H. Nagura, S. Inagi, T. Fuchigami, Chem. Commun. 2008 , 3876-3878; b) Y. Kishi, H. Nagura, S. Inagi, T. Fuchigami, Eur. J. Org. Chem. 2009, 103-109; c) U. biermann, A. Lützen, J. O. Metzger, Eur. J. Org. Chem. 2006, 2631-2637; d) A. P. Dobbs, L. Pivnevi, J. J. Penny, S. Martinovic, J. N. lley, P. T. Stephenson, Chem. Commun. 2006, 31343136; e) J. Vitale, S. D. Rychnovsky, J. Am. Chem. Soc. 2004, 126, 9904-9905; f) R. Jasti, C. D. Anderson, S. D. Rychnovsky, J. Am. Chem Soc. 2005, 127, 9939-9945; g) F. Liu, T. P. Loh, Org. Lett. 2007, 9 2063-2066; h) G. Sabitha, K. B. Reddy, M, Bhikshapathi, J. S. Yadav, Tetrahedron Lett. 2006, 47, 2807-2810; i) J. S. Yadav, B. V. S. Reddy, G. G. K. S. N. Kumar, G. M. Reddy, Chem. Lett. 2007, 36, 426-427.

[10] a) I. T. Kay, D. Bartholomew, Tetrahedron Lett. 1984, 25, 2035-2038, b) W. C. Zhang, G. S. Viswanathan, C. J. Li, Chem. Commun. 1999, 291292; c) J. S. Yadav, B. V. S. Reddy, G. M. Kumar, C. V. S. R. Murthy Tetrahedron Lett 2001, 42, 89-91; d) C. C. K. Keh, V. V. Mamboodiri, R. S. Varma, C. J. Li, Tetrahedron Lett. 2002, 43, 4993-4996; e) D. J. Hart C. E. Bennett, Org. Lett. 2003, 5, 1499-1502; f) C. S. J. Barry, S. R Crosby, J. R. Hardy, R. A. Hughes, C. D. King, G. D. Parker, C. L. Willis, Org. Lett. 2003, 5, 2499-2432; g) V. K. Yadav, N. V. Kumar. J. Am. Chem. Soc. 2004, 126, 8652-8653; h) J. S. Yadav, B. V. S. Reddy, G. G. K. S. N. Kumar, S. Aravind. Synthesis 2008, 395-400; i) K. Tadpetch, S. D. Rychnovsky, Org. Lett. 2008, 10, 4839-4842; j) B. V. S. Reddy, A Venkateswarlu, G. G. K. S. N. Kumar, A. Vinu, Tetrahedron Lett. 2010, 51, 6511-; k) T. Voigt, C. Gerding-Reimers, T. T. N. Tran, S. Bergmann, H. Lachance, B. Schölermann, A. Brockmeyer, P. Janning, S. Ziegler, H. Waldmann, Angew. Chem. Int. Ed. 2013, 52, 410-414.

[11] a) K. P. Chan, T. P. Loh, Org. Lett. 2005, 7, 4491-4494, b) K. P. Chan, Y. H. Liu, T. P. Loh, Chem. Commun. 2007, 939-941, c) F. Liu, T. P. Loh, Org. Lett. 2007, 9, 2063-2066.

[12] a) P. O. Miranda, R. M. Carballo, V. S. Martín, J. I. Padrón, Org. Lett. 2009, 11, 357-360, b) R. M. Carballo, G. Valdomir, M. Purino, V. S Martín, J. I. Padrón, Eur. J. Org. 2010, 2304-2313, c) M. Purino, M. A Ramírez, A. H. Daranas, V. S. Martín, J. I. Padrón, Org. Lett. 2012, 14 5904-5907.

[13] P. O. Miranda, L. G. León, V. S. Martín, J. I. Padrón, J. M. Padrón, Bioorg Med. Chem. Lett. 2006, 16, 3135-3138.

[14] This data is in agreement with the Loh results except in the meso type compound obtained. In our case, $5 \%$ yield of the meso-product 5 was obtained. However, $5 \%$ of the meso product 3 was obtained by Loh and co-worker using In(III) salt instead Fe(III) salts. Ref 11a.

[15] We have obtained the same results using $\mathrm{TMSCl}$ or $\mathrm{TBSCl}$ as sily additive. No difference in the ratio $4: 5$ and yields were observed.

[16] This level has been selected because a similar level $\left(\mathrm{PCM}\left(\mathrm{CH}_{2} \mathrm{Cl}_{2}\right) / \mathrm{B} 3 \mathrm{LYP} / 6-31 \mathrm{G}^{* *}\right)$ was used by Feng and co-workers in a related study (see reference [6f]).

[17] See computational details in the Supporting Information

[18] We have not detected benzyl chloride as result to benzyl carbocation formation. 


\section{FULL PAPER}

Two mechanistic pathways:

In this iron(III)-catalyzed Prins cyclization between homoallylic alcohols with non-activated alkenes two mechanistic pathways can be envisaged, namely the classical oxocarbenium and the [2+2] cyclization. Our joint experimental-DFT study supports the classical route.

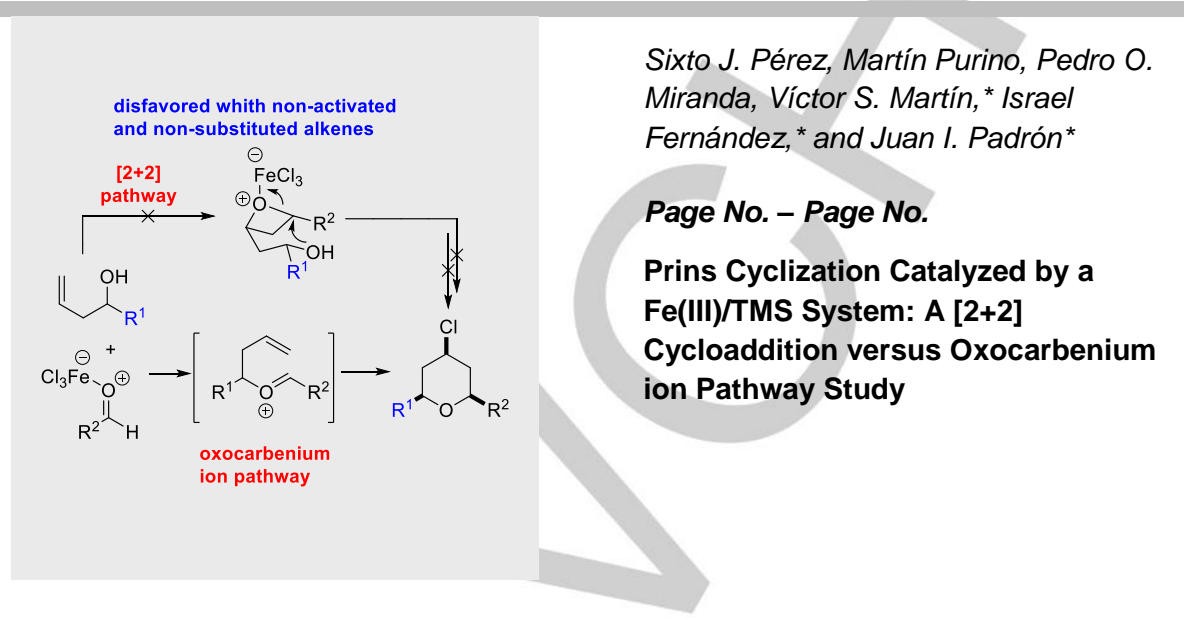

